ORIGINAL STUDY

\title{
Do the turbinates play an important role in obstructive sleep apnea syndrome? - Our experience
}

\author{
Nicoleta Dumitrescu ${ }^{1,2}$, Raluca Enache ${ }^{3}$, Codrut Sarafoleanu ${ }^{1,2,3}$ \\ ${ }^{1}$ ENT\&HNS Department, "Sfanta Maria” Hospital, Bucharest, Romania \\ 2"Carol Davila" University of Medicine and Pharmacy, Bucharest, Romania \\ ${ }^{3}$ ENT Sarafoleanu Medical Clinic, Bucharest, Romania
}

\section{ABSTRACT}

BACKGROUND. Nasal obstruction may trigger obstructive sleep apnea syndrome (OSAS) and it is considered to be a cofactor in its pathophysiology. However, the relation between cause and effect still remains a matter of debate.

MATERIAL AND METHODS. 18 patients diagnosed with chronic hypertrophic rhinitis and obstructive sleep apnea syndrome were included in the present study. All patients underwent nasal surgery as the single treatment for their sleep breathing disorders. Rhinomanometric (total nasal airflow, logReff, logVR) and polygraphic parameters (apnea-hypopnea index - AHI, snore flags index - SFI) were evaluated pre- and 2 months postoperatively.

RESULTS. There was a statistically significant difference between the values of the preoperative and postoperative total nasal airflow ( $\mathrm{p}$-value $<0.0001$ ). In case of AHI, there was a decrease in its value from 31.56 preoperatively to 30.03 postoperatively, but the difference was not statistically significant $(\mathrm{p}=0.937)$. The SFI, on the other hand, presented a significant decrease $(p=0.05)$, from a mean value of 93.15 preoperatively to 56.02 after the surgery. The correlation of the total nasal airflow with AHI and SFI, revealed that nasal surgery had an important impact upon snoring characteristics (r=0.24) and less upon OSAS severity $(\mathrm{r}=0.21)$.

CONCLUSION. The nasal cavity obstruction contributes less to OSAS, but still represents a disorder that needs to be corrected in case of such patients. Turbinates reduction surgery may be applied in the treatment of OSAS and combined with palate and/ or tongue surgery.

KEYWORDS: obstructive sleep apnea syndrome, nasal resistance, turbinates reduction, respiratory polygraphy

\section{INTRODUCTION}

The nasal obstruction may be a trigger for the obstructive sleep apnea syndrome (OSAS) in normal individuals and it is considered to be a co-factor in the pathophysiology of OSAS. However, the relation between cause and effect still remains a matter of debate ${ }^{1}$.

There are multiple surgical options available for treating nasal symptoms due to inferior turbinate hypertrophy. Commonly, a surgical reduction of the turbinate is indicated if a three-month conservative therapy has not had any subjective and objective success. Frequently, surgery is offered empirically, there being a great discrepancy between the subjective complaint of nasal obstruction and the surgeon's clinical examination. Furthermore, the meta-analysis attempts collided with the lack of homogeneous study cohorts, in the literature being only two studies having as yet achieved evidence level $2^{2-4}$.

In this study, we present our experience in order to determine the implication of nasal obstruction in the pathophysiology of obstructive sleep apnea.

\section{MATERIAL AND METHODS}

We included in our study 18 patients (aged between 33 - 63; mean age $=46.3+/-8.6 ; \mathrm{M}: \mathrm{F}=14: 4)$ diagnosed with chronic hypertrophic rhinitis and obstructive 
sleep apnea syndrome. All patients performed a 4-phase-rhinomanometry, for the evaluation of the degree and the cause of the nasal obstruction, and a respiratory polygraphy, for the diagnosis of the sleepbreathing disorders.

The nasal surgery consisted in radiofrequency inferior turbinates reduction. Postoperative rhinomanometric and polygraphic findings were assessed 2-month after surgery.

The evaluated parameters were the total nasal airflow $(\mathrm{ccm} / \mathrm{s})$ at $150 \mathrm{~Pa}$ pressure, log Reff (logarithmic Effective Resistance), log VR (logarithmic Vertex Resistance), AHI (Apnea-Hypopnea Index) and SFI (Snore Flags Index). The logarithmic Effective Resistance evaluates the work of nasal breathing and it is correlated with the subjective sensation of obstruction, while the logarithmic Vertex Resistance is the resistance of the nasal airstream at the point of maximum flow during inspiration or expiration ${ }^{5}$.

The data was processed in Excel 2007 and the statistical analysis was performed using XLSTAT 2015.

\section{RESULTS}

Analysing the pre- and postoperative rhinomanometric results, we observed statistically significant improvement in the total nasal airflow and total nasal resistance between the two measurements performed before decongestion.

Preoperatively, the total nasal airflow varied between 142 and $534 \mathrm{ccm} / \mathrm{s}$, with a mean of 339.5 , before decon- gestion, and between 550 and $960 \mathrm{ccm} / \mathrm{s}$, mean value $=$ 775.78, after decongestion (Figure 1). The difference between the two measurements proved to be statistically significant, with a $\mathrm{p}$-value $<0.05$. Postoperatory measurements revealed a total nasal airflow between 450 and $852 \mathrm{ccm} / \mathrm{s}$, mean $=690.67$, before decongestion, and 662 and $1214 \mathrm{ccm} / \mathrm{s}$, mean $=886.78$, after decongestion. After surgery, there may not be observed the same considerable variation, but there are roughly normal parameter values before and after nasal decongestion. Because the results in airflow are comparable preoperatively after decongestion and postoperatively before decongestion, we may conclude that the preoperatory nasal decongestion values may be considered a predictive factor of nasal surgery success in case of mucosal hypertrophy of the inferior turbinates.

Considering the total nasal resistance variation, before and after the surgical procedure, we can observe a statistically significant decrease in both log Reff (Figure 2) and $\log$ VR values (Figure 3).

From the respiratory polygraphy parameters, we took into consideration the apnea-hypopnea index (AHI) and the snore flags index (SFI). In case of AHI, there was a decrease in its value from 31.56 preoperatively to 30.03 postoperatively, but the difference was not statistically significant $(p=0.937)$ (Figure 4). SFI, on the other hand, presented a significant decrease $(\mathrm{p}=0.05)$, from a mean value of 93.15 preoperatively to 56.02 after the surgery (Figure 4 ). So, we can say that nasal surgery had an important impact upon snoring characteristics and less upon OSAS severity $(r=0.21)$ (Figure 5).

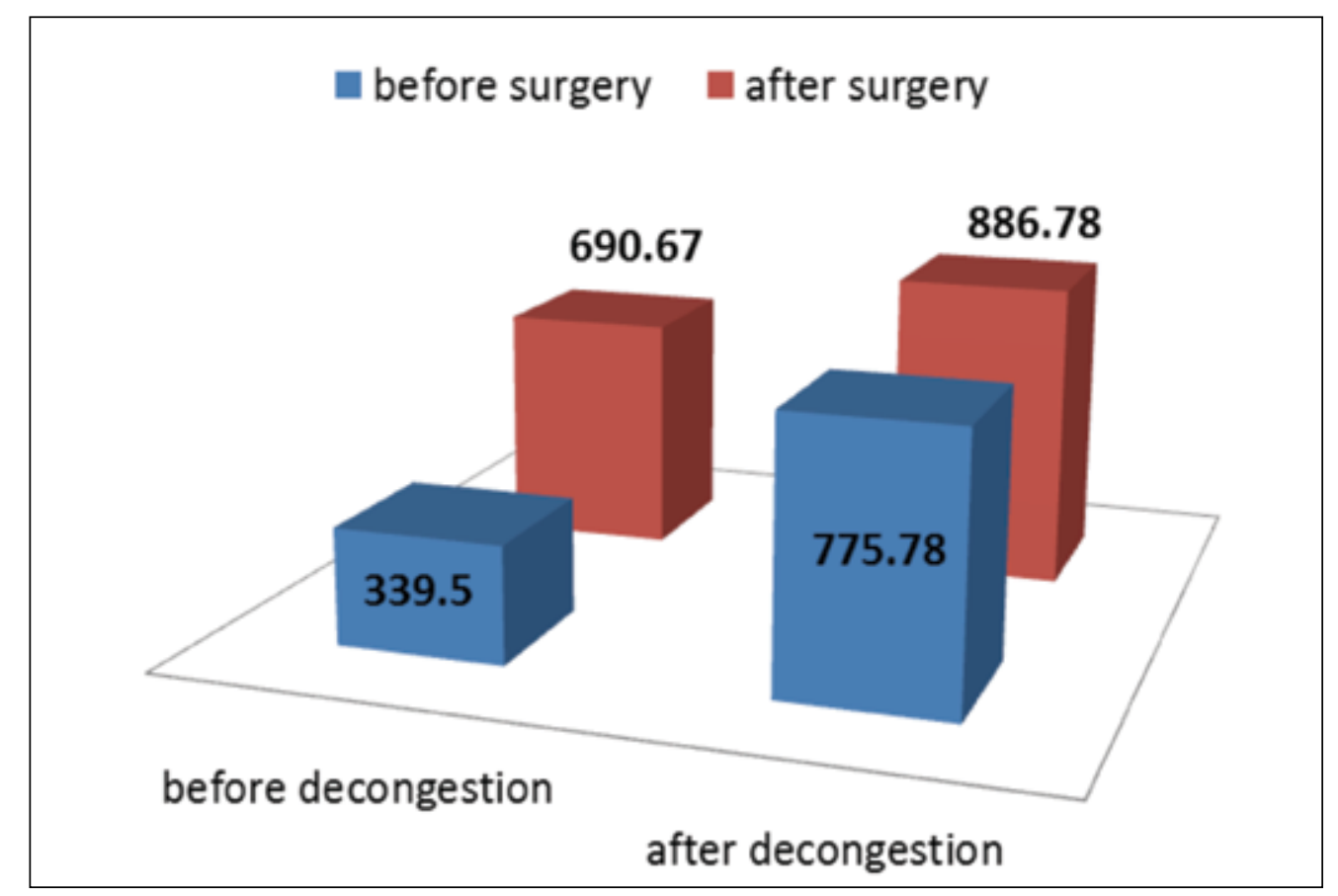

Figure 1 Total nasal airflow variation 


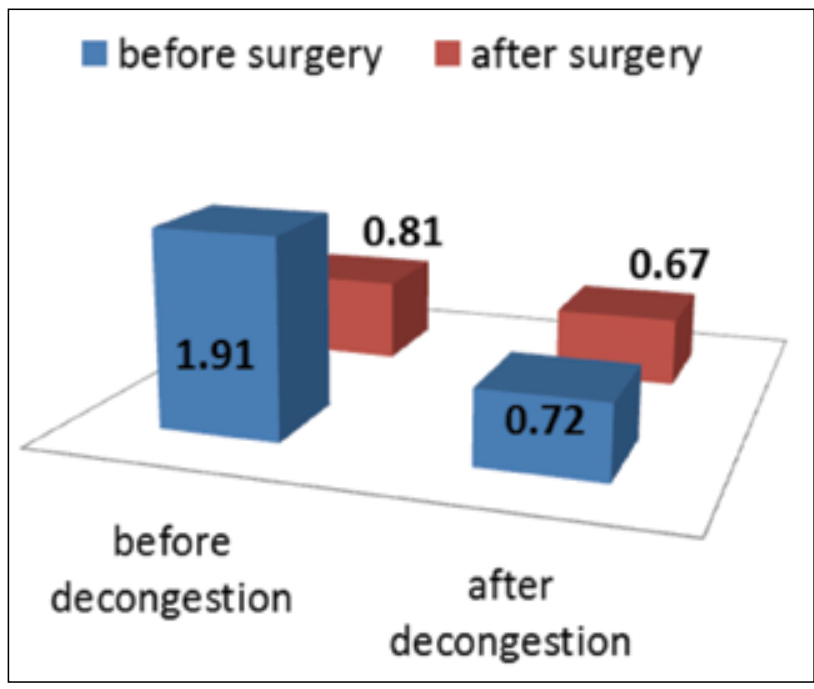

Figure 2 Log Reff variation

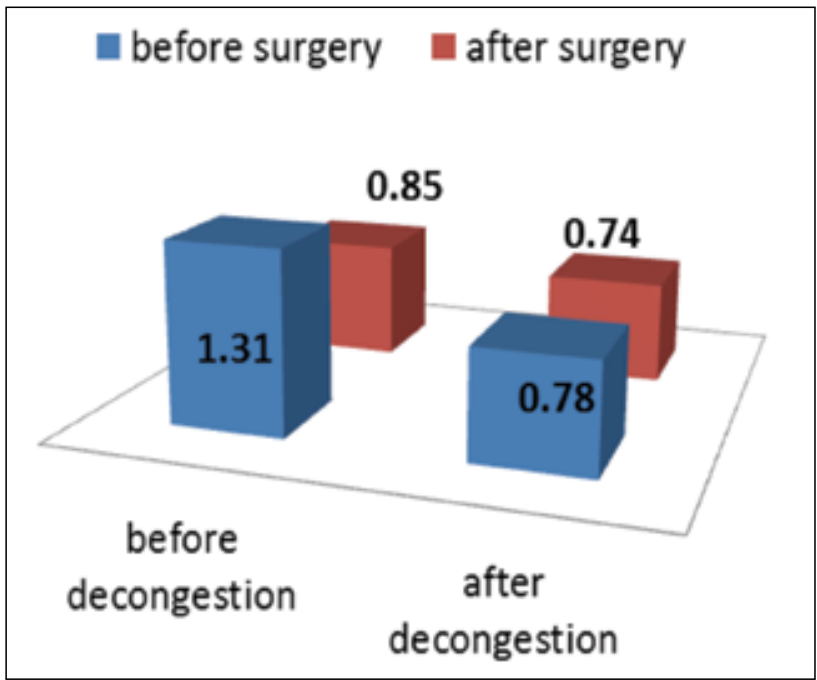

Figure 3 Log VR variation

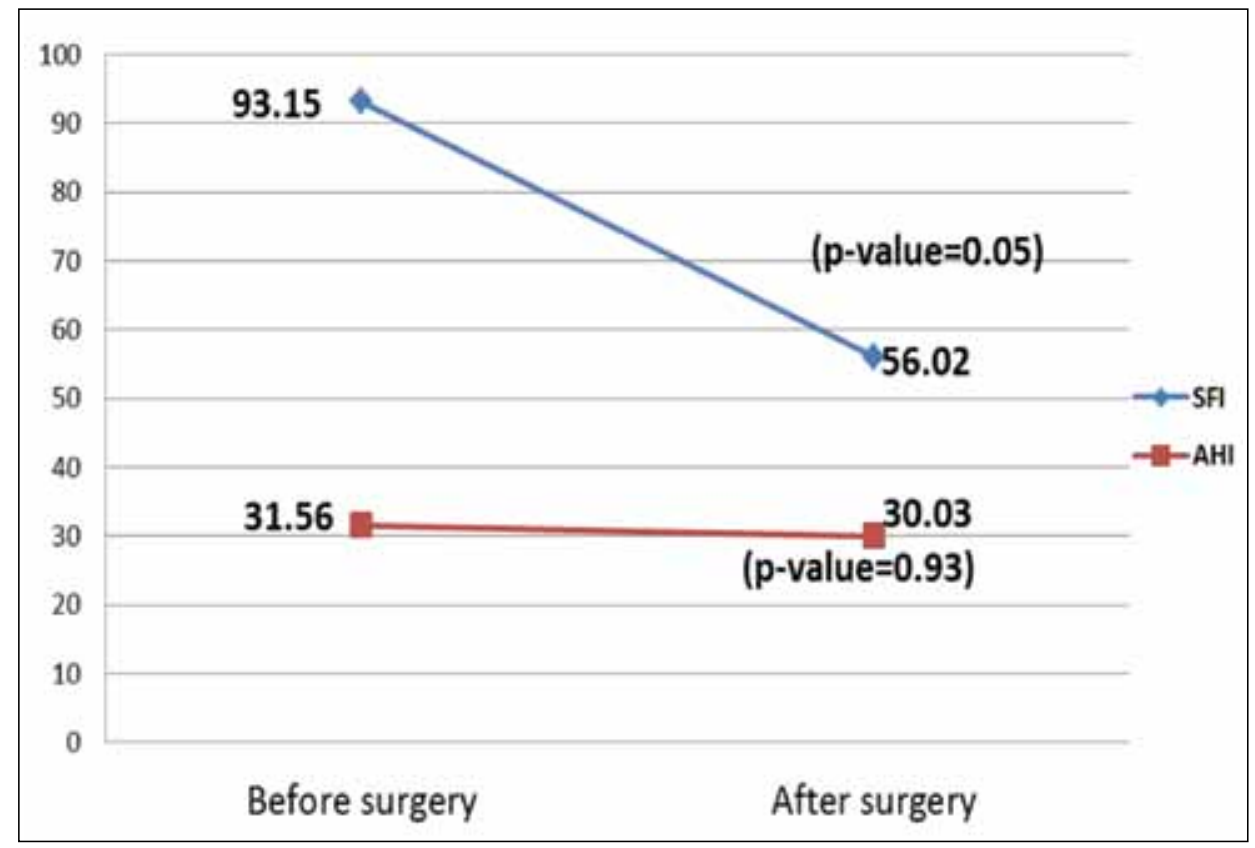

Figure $4 \mathrm{AHI}$ and SFI variation

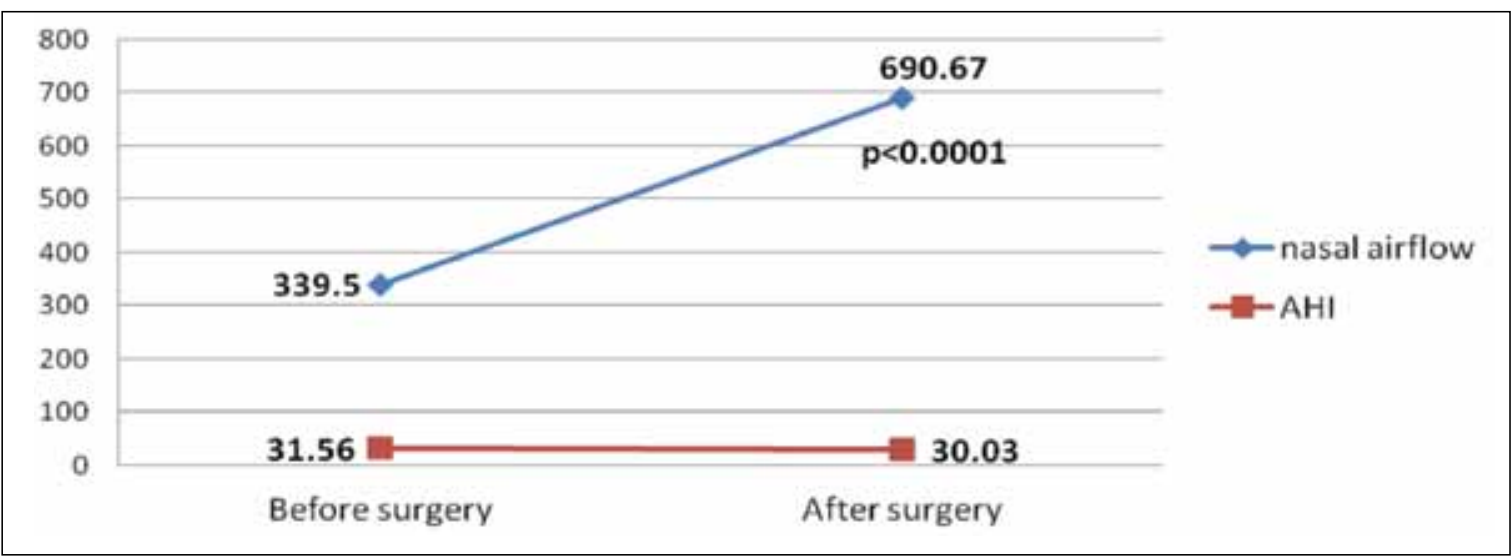

Figure 5 Correlation between nasal airflow and AHI 


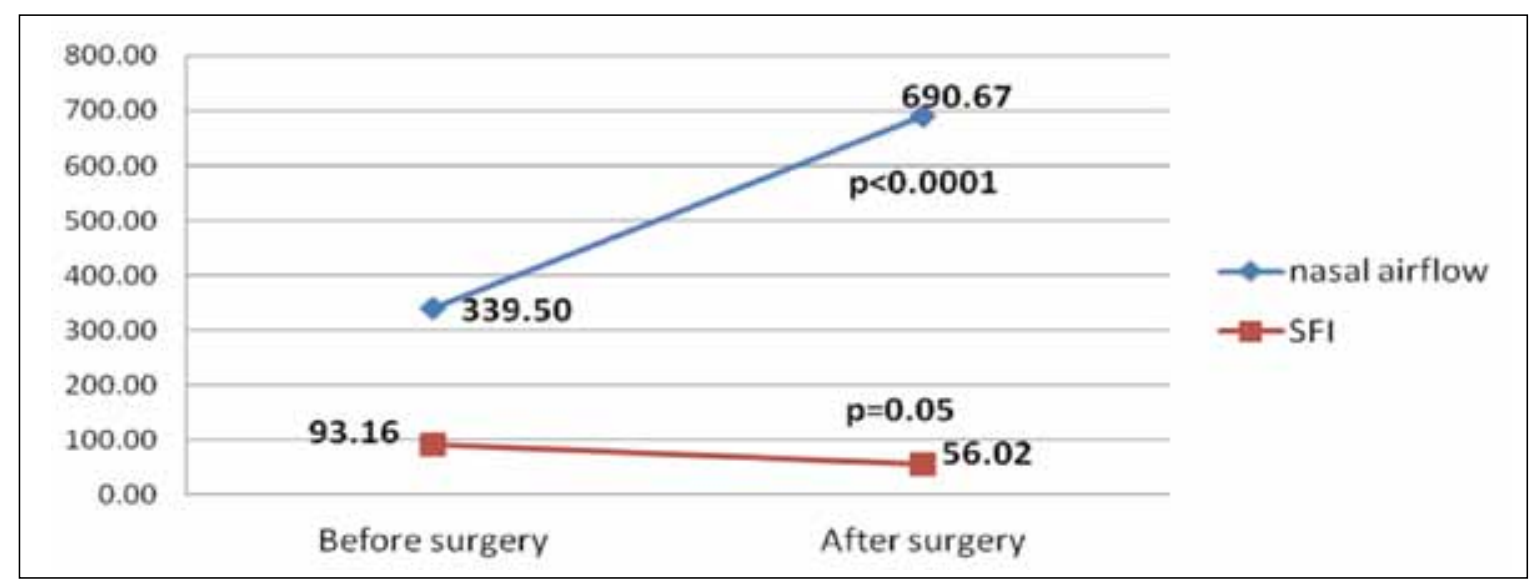

Figure 5 Correlation between nasal airflow and SFI

There is a significant reduction in the number of snoring episodes per hour and a major increase in the nasal airflow. Nevertheless, there is a weak correlation between the improvement of the nasal airflow and the frequency of snoring episodes $(\mathrm{r}=0.24)$ (Figure 6).

\section{DISCUSSIONS}

The consequences of daily nasal obstruction on sleep quality have been well demonstrated, resulting in poor sleep quality, daytime discomfort and fatigue. Furthermore, the nasal pathology may have an important impact on OSAS severity ${ }^{6}$, the phenomenon being observed in the case of impaired nasal breathing in sensitized subjects during high allergen exposure and in patients with common cold during the night.

Even if nasal obstruction is considered to be cofactor in the pathophysiology of OSAS, the relation between cause and effect is still a matter of debate. The experimental evidence of the role of nasal obstruction on sleep quality revealed pro and con arguments in this regard.

Zwillich and Olsen used polysomnography in two independent studies, discovering that sleep quality worsened in healthy men with nostrils occluded, using petroleum jelly and cotton or adhesive tapes, leading to obstructive hypopnea and apnea ${ }^{7,8}$. Wetmore et al. revealed that complete nasal packing in epistaxis patients induced similar effects represented by apneas and desaturation episodes ${ }^{9}$. Liistro et al. studied 202 patients referred for the assessment of sleep-related breathing disorders (SRDB) and found a correlation between the Mallampati score, nasal examination and sleep parameters; thus, a high Mallampati score (MS) with concomitant nasal obstruction is associated with a high risk of OSAS (the MS is associated with AHI only in the presence of nasal obstruction $)^{10}$. Patients with SRBD switch more frequently from nasal to oronasal breathing during sleep if nasal obstruction is present, leading to an increased respiratory effort and alveolar hypoventilation ${ }^{10-12}$.

Virkkula et al. assessed 41 patients referred for snoring, revealing a direct relationship between total nasal resistance, AHI $(\mathrm{r}=0.50, \mathrm{p}<0.05)$ and oxygen desaturation $(\mathrm{r}=0.58, \mathrm{p}<0.05)$ measured in patients in the supine position ${ }^{13}$.

Other cohort studies revealed that patients with night-time symptoms of rhinitis or nasal congestion have a higher risk of developing OSAS and snoring ${ }^{14,15}$.

Contrariwise, regarding the relation between nasal patency and OSAS in patients with abnormal nasal patency, Miljeteig et al. studied 683 patients diagnosed with snoring and/or apnea, assessing the nasal resistance and the sleep parameters. They found no correlation between the unilateral or bilateral increase of nasal resistance and snoring or apnea and no direct relation between seated nasal resistances, awakened state and sleep parameters ${ }^{16}$. No evidence of the role of nasal obstruction on sleep quality was also confirmed by others authors ${ }^{17,18}$.

The effects of nasal surgery on snoring and obstructive sleep apnea syndrome are also a matter of debate. Definition of surgical success is defined, after Sher, as $50 \%$ improvement in respiratory disturbance index (RDI) to a final absolute value below 20, or the apneahypopnea index (AHI) to below $10^{19}$. In case of the effect of nasal and sinus surgery on OSAS, although some of the studies found in the literature have demonstrated a slight decrease in the AHI for some patients, the success rate proved to be very $\operatorname{low}^{6,20-28}$. Regarding the snoring episodes, the clinical data found in the literature reveals that the improvement in nasal resistance reduces snoring episodes and even ceases them for some patients ${ }^{6,29-32}$. So, isolated nasal surgical success may be difficult to objectify regarding snoring, being about $40 \%$ of cases with cessation of snoring and about $85 \%$ with reduction in sound intensity (by $5-10 \mathrm{~dB})^{6,33}$; in case of OSAS, the surgical success seems to be about $10-20 \%$. 
A study performed by Kim et al. in 2004 on 21 patients evaluated the effects of nasal surgery (septoplasty with or without turbinectomy) on snoring and apnea $^{23}$. They reported a decrease of the AHI from 39 to $29(\mathrm{p}=0.0001)$ and of the snoring duration from $44 \%$ to $39 \%(\mathrm{p}=0.1595)$. In another study performed on 26 adult patients diagnosed with sleep-related breathing disorders, Verse T. and Pirsig W. observed no significant difference between the AHI value before nasal surgery $(\mathrm{AHI}=31.6)$ and the $\mathrm{AHI}$ value after the surgery $(\mathrm{AHI}=28.9)$, despite the significant improvement of the nasal resistance $(\mathrm{p}=0.0089)^{28}$. Our results can be compared with those reported above.

All the studies found in the literature reveal that nasal surgery reduces the requested nasal continuous positive airway pressure (CPAP) and improves patients' compliance with this therapy $y^{6,24,34-38}$.

There are also authors reporting an increase in the severity of the apnea syndrome (of the AHI) after the nasal surgery ${ }^{27,39,40}$. Nasal surgery may be ineffective if cranio-mandibular abnormalities and an important pharyngeal collapse co-exist, which is why the selection of appropriate surgical procedures for reconstruction of the upper airway may represent the most difficult task for the surgeon; in most cases, a multiphase approach is preferable.

\section{CONCLUSIONS}

The turbinates play a debatable role in OSAS, but some authors claim that nasal obstruction may trigger the induction of OSAS in normal individuals. Nasal surgery (including inferior turbinates) seems to improve some parameters, but few studies with statistical significance are available. The turbinates reduction improves nasal breathing and pharyngeal patency, which reduces the CPAP pressure.

Even though nasal surgery may be ineffective as single treatment for OSAS, it has proved very useful in treating snorers, reducing CPAP pressure and being part of the multilevel approach.

From our experience, we also sustain the idea that in OSAS treatment, nasal surgery must be part of a multilevel surgery plan.

Conflict of interest: The authors have no conflict of interest.

Contribution of authors: All authors have equally contributed to this work.

\section{REFERENCES}

1. Rappai M., Collop N., Kemp S., deShazo R. - The nose and sleep-disordered breathing: What we know and what we do not know. Chest,
2003;124(6):2309-2323.

2. Scheithauer M.O. - Surgery of the turbinates and "empty nose" syndrome. GMS Curr Top Otorhinolaryngol Head Neck Surg., 2010;9:Doc03. Published online 2011 Apr 27. doi: 10.3205/cto000067.

3. Passali D., Passali F.M., Damiani V., Passali G.C., Bellussi L. - Treatment of inferior turbinate hypertrophy: a randomized clinical trail. Ann Otol Rhinol Laryngol., 2003;112(8):683-688.

4. Joniau S., Wong I., Rajapaksa S., Carney S.A., Wormald P.J. - Longterm comparison between submucosal cauterization and powered reduction of the inferior turbinates. Laryngoscope, 2006;116(9):1612-1616.

5. Vogt K., Shah-Hosseini K., Mosges R., Pallanch J., Hasse W. - New parameters in 4-phase-rhinomanometry, relations between objective findings and the sensation of obstruction. A statistical evaluation of 1580 cases. Rhinology, 2010;Suppl 21:25-31.

6. Verse T., Pirsig W. - Nasal surgery. In: Hörmann K., Verse T. - Surgery for Sleep Disordered Breathing. 2nd Edition. Springer-Verlag Berlin Heidelberg 2010, 2005;p.35-41.

7. Zwillich C.W., Pickett C., Hanson F.N., Weil J.V. - Disrupted sleep and prolonged apnea during nasal obstruction in normal men. Am Rev Respir Dis., 1981;124:158-160.

8. Olsen K.D., Kern E.B., Westbrook P.R. - Sleep and breathing disturbances secondary to nasal obstruction. Otolaryngol Head Neck Surg., 1981;89:804-810.

9. Wetmore S.J., Scrima L., Hiller F.C. - Sleep apnea in epistaxis patients treated with nasal packs. Otolaryngol Head Neck Surgery, 1988;98:596-599.

10. Liistro G., Rombaux Ph., Belge C., Dury M., Aubert G., Rodenstein D. High Mallampati score and nasal obstruction are associated risk factors for obstructive sleep apnea. Eur Respir J., 2003;21:248-252.

11. De Vito A. - The importance of nasal resistance in obstruction sleep apnea syndrome: a study with positional rhinomanometry. Sleep Breath, 2001;5:3-11.

12. Ohki M., Usui N., Kanazawa H., Hara I., Kawano K. - Relationship between oral breathing and nasal obstruction in patients with obstruction sleep apnea. Acta Otolaryngol Suppl., 1996;52:228-230.

13. Virkkula P., Maasilta P., Hytonen M., Salmi T., Malmberg H. - Nasal obstruction and sleep-disordered breathing: the effects of supine body position on nasal measurements in snorers. Acta Otolaryngol (Stockh), 2003;123:648-654.

14. Metes A., Cole P., Hoffstein V., Miljeteig H. - Nasal airway dilation and obstructed breathing in sleep. Laryngoscope, 1992;102:1053-1055.

15. Young T., Finn L., Kim H. - Chronic nasal congestion at night is a risk factor for snoring: in population - based cohort study. Arch Intern Med., 2001;161:1514-1519.

16. Miljeteig H., Hoffstein V., Cole P. - The effects of unilateral and bilateral nasal obstruction on snoring and sleep apnea. Laryngoscope, 1993;102:1150-1152.

17. Miljeteig H., Savard P., Mateika S., Cole P., Haight J.S., Hoffstein V. Snoring and nasal resistance during sleep. Laryngoscope, 1993;103:918923.

18. Jessen M., Fryrsmark U. - Is there a relationship between the degree of nasal obstruction and the snoring ? Clin Otolaryngol., 1993;18:485-487.

19. Sher A.E., Schechtman K.B., Piccirillo J.F. - The efficacy of surgical modifications of the upper airway in adults with obstructive sleep apnea syndrome. Sleep, 1996;19:156-177.

20. Rubin A.H., Eliaschar I., Joachim Z., Alroy G., Lavie P. - Effects of nasal surgery and tonsillectomy on sleep apnea. Bull Eur Physiopathol Respir. 1983;19:612-615.

21. Dayal V.S., Phillipson E.A. - Nasal surgery in the management of sleep apnea. Ann Otol Rhinol Laryngol., 1985;94:550-554.

22. Caldarelli D.D., Cartwright R., Lilie J.K. - Obstructive sleep apnea: variations in surgical management. Laryngoscope, 1985;95:1070-1073. 
23. Kim S.T., Choi J.H., Jeon H.G., Cha H.E., Kim D.Y., Chung Y.S. Polysomnographic effects of nasal surgery for snoring and obstructive sleep apnea. Acta Otolaryngol., 2004;124:297-300.

24. Friedman M., Tanyeri H., Lim J.W., Landsberg R., Vaidyanathan K., Caldarelli D. - Effect of improved nasal breathing on obstructive sleep apnea. Otolaryngol Head Neck Surg., 2000;122:71-74.

25. Sériès F., Pierre S. St, Carrier G. - Effects of surgical correction of nasal obstruction in the treatment of obstructive sleep apnea. Am Rev Respir Dis., 1992;146:1261-1265.

26. Sériès F., Pierre S. St, Carrier G. - Surgical correction of nasal obstruction in the treatment of mild sleep apnoea: importance of cephalometry in predicting outcome. Thorax, 1993;48:360-363.

27. Utley D.S., Shin E.J., Clerk A.A., Terris D.J. - A cost-effective and rational surgical approach to patients with snoring, upper airway resistance syndrome, or obstructive sleep apnea syndrome. Laryngoscope, 1997;107:726-734.

28. Verse T., Maurer J.T., Pirsig W. - Effect of nasal surgery on sleep related breathing disorders. Laryngoscope, 2002;112:64-68.

29. Fairbanks D.N.F. - Snoring: surgical vs. nonsurgical management. Laryngoscope, 1984;94:1188-1192.

30. Ellis PDM, Harris MLL, Williams JE, Shneerson JM. The relief of snoring by nasal surgery. Clin Otolaryngol 1992;17:525-527.

31. Elsherif I., Hussein S.N. - The effect of nasal surgery in snoring. Am J Rhinol., 1998;12:77-79.

32. Bertrand B., Eloy P., Collet S., Remarque C., Rombeaux P. - Effect of nasal valve surgery by open-septorhinoplasty and lateral cartilage grafts (spreader grafts) on snoring among a population of single snorers. Preliminary report. Acta Otorhinolaryngol Belg., 2002;56:149-155.
33. Schäfer J. - Spektralanalyse pathologischer schlafabhängiger Atemgeräusche der oberen Luftwege unter besonderer Berücksichtigung der Diagnostik und Therapie des obstruktiven Schlafapnoe-Syndroms und chronischer Rhonchopathien [in German]. University of Ulm, Ulm, Germany, 1990, Thesis.

34. Mayer-Brix J., Becker H., Peter J.H. - Nasal high pressure ventilation in obstructive sleep apnea syndrome. Theoretical and practical otorhinolaryngologic aspects [in German]. Laryngorhinootologie, 1989;68:295-298.

35. Dorn M., Pirsig W., Verse T. - Management of patients with severe obstructive sleep apnea following rhinosurgical interventions. A pilot study [in German]. HNO, 2001;49:642-645.

36. Masdon J.L., Magnuson J.S., Youngblood G. - The effects of upper airway surgery for obstructive sleep apnea on nasal continuous positive airway pressure settings. Laryngoscope, 2004;114:205-207.

37. Nakata S., Noda A., Yagi H., Yanafi E., Mimura T., Okada T., Misawa H., Nakashima T. - Nasal resistance for determinant factor of nasal surgery in CPAP failure patients with obstructive sleep apnea syndrome. Rhinology, 2005;44:296-299.

38. Zonato A.I., Bittencourt L.R., Martinho F.L., Gregório L.C., Tufik S. Upper airway surgery: the effect on nasal continuous positive airway pressure titration on obstructive sleep apnea patients. Eur Arch Otorhinolaryngol., 2006;263:481-486.

39. Verse T., Pirsig W., Kroker B.A. - Obstructive sleep apnea and nasal polyps [in German]. Laryngorhinootologie, 1998;77:150-152.

40. Virkkula P., Bachour A., Hytönen M., Salmi T., Malmberg H., Hurmerinta K., Maasilta P. - Snoring is not relieved by nasal surgery despite improvement in nasal resistance. Chest, 2006;129:81-87. 